\title{
Anti-CD6 Humanized Monoclonal Antibody Itolizumab, Halts Disease Progression and Severity of Acute Respiratory Distress Syndrome in COVID-19 Disease: A Case Study
}

\author{
Hemant P. Thacker, Amit Dhekane' ${ }^{1}$, Nivedita Wadhwa', Shalaka Patil ${ }^{1}$ \\ Departments of General Medicine and ${ }^{1}$ Critical Care Medicine, Bhatia Hospital, Mumbai, Maharashtra, India
}

\section{Abstract}

In COVID-19 patients, cytokine release syndrome plays a critical role in disease progression. Itolizumab inhibits T-cell proliferation and differentiation, thereby modulating imminent cytokine storm. Here, we report a case of a 44-year-old male patient with confirmed COVID-19 and oxygen saturation $\left(\mathrm{SpO}_{2}\right)$ of $88 \%$ on room air. A chest X-ray revealed dense opacification. High levels of inflammatory markers such as C-reactive protein (CRP) and ferritin were observed. The patient's $\mathrm{SpO}_{2}$ decreased to $87 \%$ on day 4 despite the best supportive care. Itolizumab was then administered at $1.6 \mathrm{mg} / \mathrm{kg}$ along with high flow oxygen. The patient's $\mathrm{SpO}_{2}$ values improved to $95 \%$ and $97 \%$ on $4^{\text {th }}$ - and $5^{\text {th }}$-day postinfusion, respectively. CRP and ferritin levels decreased by $85.96 \%$ and $24.48 \%$, respectively, along with radiological improvement. The patient was discharged on the $7^{\text {th }}$ day postinfusion in a clinically stable condition. This is the first report of an anti-CD6 humanized monoclonal antibody, itolizumab, given to a patient with moderate-to-severe COVID-19 disease that showed a reduction in hyperinflammation, leading to clinical and radiological improvement.

Keywords: Acute respiratory distress syndrome, CD6, COVID-19, cytokine storm, hyperinflammation, itolizumab

\section{INTRODUCTION}

Novel coronavirus disease (COVID-19) was declared a global pandemic by the World Health Organization (WHO) on March 11, 2020. With no known cure to the disease, multiple options are being considered to reduce symptoms and mortality.

COVID-19 is marked with an increase in pro-inflammatory cytokines released by activated T-cells. Uncontrolled inflammation can lead to acute respiratory distress syndrome (ARDS), sepsis, multiorgan dysfunction syndrome, and death. ${ }^{[1]}$ T-cells are activated by the binding of the activated leukocyte cell adhesion molecule (ALCAM/CD166) found on antigen-presenting cells, with the CD6 receptor on T-cells [Figure 1a]..$^{[2]}$ This is a crucial step in T-cell proliferation to form helper T-cells (Th1 and Th17 cells), which in turn produce inflammatory cytokines such as interferon gamma, tumor necrosis factor-alpha, interleukin (IL)-2, IL-6, IL-10, IL-17, IL-22, granulocyte colony-stimulating factor, and others [Figure 1b]. ${ }^{[3]}$

Itolizumab is a humanized recombinant immunoglobulin G1 monoclonal antibody which targets domain 1 of CD6,

\begin{tabular}{|l|l|}
\hline \multicolumn{2}{|c|}{ Access this article online } \\
\hline Quick Response Code: & Website: \\
\hline & www.ijrc.in \\
\hline & \\
\hline
\end{tabular}

thereby modulating T-lymphocyte activation, proliferation, and differentiation induced by CD6 co-stimulation [Figure 1c]. It does not cause T-cell depletion as it does not inhibit soluble ALCAM binding. In addition, it is believed that the presence of $\mathrm{CD} 6$ in $\mathrm{T}$ - and $\mathrm{B}$-cells provides a wider range of immunomodulating effects. ${ }^{[4]}$

Here, we present a case study of a 44-year-old, COVID-19 male patient with multiple comorbidities treated with itolizumab, who was deteriorating with low oxygen saturation $\left(\mathrm{SpO}_{2}\right)$ of $87 \%$ and high inflammatory markers despite best supportive care. The patient's medical history included diabetes, hypertension, and stroke in 2014.

Address for correspondence: Dr. Hemant $P$. Thacker, Bhatia Hospital, Tardeo Road, Old Chikalwadi, Grant Road (W), Tardeo, Mumbai - 400 007, Maharashtra, India. E-mail: drhpt@hotmail.com

This is an open access journal, and articles are distributed under the terms of the Creative Commons Attribution-NonCommercial-ShareAlike 4.0 License, which allows others to remix, tweak, and build upon the work non-commercially, as long as appropriate credit is given and the new creations are licensed under the identical terms.

For reprints contact: WKHLRPMedknow_reprints@wolterskluwer.com

How to cite this article: Thacker HP, Dhekane A, Wadhwa N, Patil S. AntiCD6 humanized monoclonal antibody itolizumab, halts disease progression and severity of acute respiratory distress syndrome in COVID-19 disease: A case study. Indian J Respir Care 2021;10:112-5.

Received: $30-07-2020$

Accepted: 07-09-2020 Published: 31-01-2021 
Thacker, et al.: A case study on COVID-19 patient treated with itolizumab

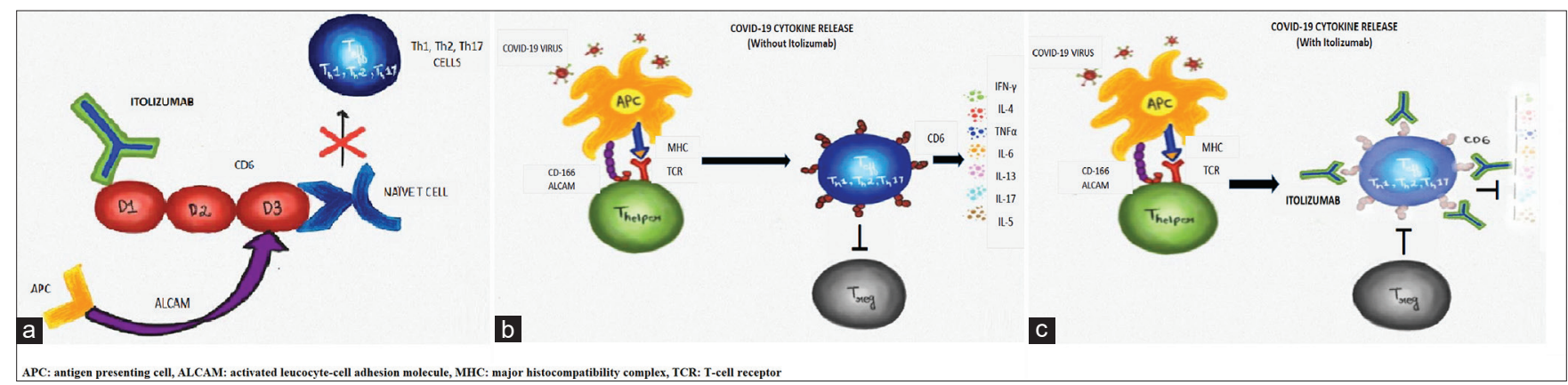

Figure 1: (a) Binding of itolizumab to domain 1 of naïve T-cell, (b) T-cell proliferation and cytokine storm in the absence of itolizumab, (c) absence of T-cell proliferation and cytokine storm in the presence of itolizumab

\section{Case Report}

The patient was presented on June 2, 2020, with a history of fever, cough, weakness, and body pain. His body weight was $62 \mathrm{~kg}$. There was no history of diarrhea, headache, or sore throat. The patient was on antihypertensive (amlodipine $5 \mathrm{mg}$ OD) and antidiabetic drugs including SGLT2 inhibitor (remogliflozin $500 \mathrm{mg} \mathrm{BD}$ ), DPP-IV inhibitor (evogliptin 5 $\mathrm{mg}$ OD), rosuvastatin $20 \mathrm{mg}$ OD and aspirin $150 \mathrm{mg}$ OD. The patient tested positive for SARS-CoV-2 infection by reverse transcription- polymerase chain reaction (RT-PCR).

On examination, his respiratory rate (RR) was $22 / \mathrm{min}$, with $\mathrm{SpO}_{2}$ of $88 \%$ on room air. Upon admission, the patient was administered oxygen $(2-4 \mathrm{~L} / \mathrm{min}$ ) through nasal prongs and the $\mathrm{SpO}_{2}$ improved to $92 \%$. His clinical status score was 4 based on an 8-point ordinal scale.

On $3^{\text {rd }}$ June, the patient was shifted to a Venturi mask with an oxygen flow of $8 \mathrm{~L} / \mathrm{min}$, and his oxygen saturation was maintained at $92 \%$. His inflammatory markers were elevated: C-reactive protein (CRP) $183.24 \mathrm{mg} / \mathrm{mL}$, ferritin $633.7 \mathrm{ng} /$ $\mathrm{mL}$, and his chest X-ray revealed bilateral basal peripheral and upper lobe complete dense opacification.

On $4^{\text {th }}$ June, the oxygen flow was increased to $12 \mathrm{~L} / \mathrm{min}$ through high flow nasal cannula (HFNC), and the patient maintained $\mathrm{SpO}_{2}$ of $90 \%$. Chest X-ray revealed persistent opacities in bilateral basal peripheral zones.

On $5^{\text {th }}$ June, the patient had a reduced $\mathrm{SpO}_{2}$ of $87 \%$ with HFNC $(12-14 \mathrm{~L} / \mathrm{min})$ and RR of $32 / \mathrm{min}$. Itolizumab $(1.6 \mathrm{mg} / \mathrm{kg})$ was consequently administered as an intravenous infusion with $250 \mathrm{ml}$ of normal saline for 5-6 $\mathrm{h}$ after premedication with hydrocortisone $100 \mathrm{mg}$ IV, $30 \mathrm{~min}$ before itolizumab infusion. The infusion was well tolerated. The patient continued to be on high flow oxygen (10-12 L/min) until 4-day postitolizumab infusion and maintained a $\mathrm{SpO}_{2}$ of $95 \%$.

Five-day postinfusion, the patient was shifted to a Venturi mask and then to oxygen by nasal prongs; oxygen flow was reduced to 4-6 L/min. The patient maintained a $\mathrm{SpO}_{2}$ of $97 \%$, and his chest $\mathrm{X}$-ray revealed signs of improvement with fibrotic changes.

Six-day postinfusion, the patient was clinically stable and was off oxygen. The clinical improvement as per the WHO

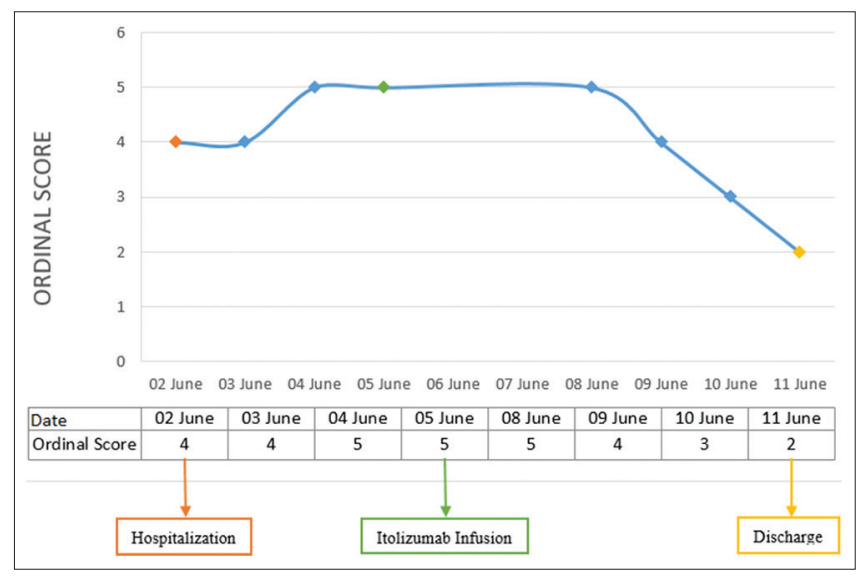

Figure 2: Change in patient's ordinal score from hospitalization to discharge

ordinal scale [Table 1] is shown in Figure 2. A significant reduction in inflammatory markers such as serum CRP and ferritin $(25.73 \mathrm{mg} / \mathrm{mL}$ and $478.6 \mathrm{ng} / \mathrm{mL}$, respectively) was also observed. In addition, the radiological improvement was evident as shown by healing with fibrosis.

The patient was discharged on June 11, 2020 (7-day postinfusion).

Predose chest X-ray images are provided in Figures 3 and 4. Figure 5 shows a postdose image.

\section{Discussion}

COVID-19 is a global pandemic, and India has seen a sudden upsurge in the number of positive cases. While the majority of cases present with mild symptoms and good prognosis, around $20 \%$ of cases progress to severe and critical diseases. ${ }^{[5]}$ Several studies have shown an increase in inflammatory cytokines in COVID-19 patients. $^{[6]}$

Inflammatory markers such as procalcitonin, serum ferritin, erythrocyte sedimentation rate, CRP, and IL-6 have been shown to be correlated with prognosis in COVID-19. ${ }^{[7]}$ Serum ferritin levels increase in inflammation, liver disease, and malignancy ${ }^{[8]}$ and can highlight an overexuberant inflammatory response associated with the severity of COVID-19. 


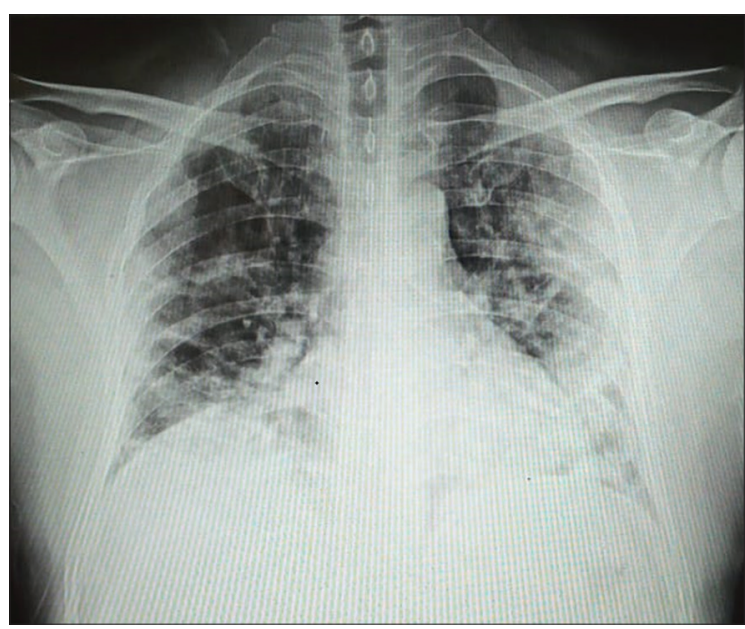

Figure 3: Predose chest X-ray image (on June 3, 2020)

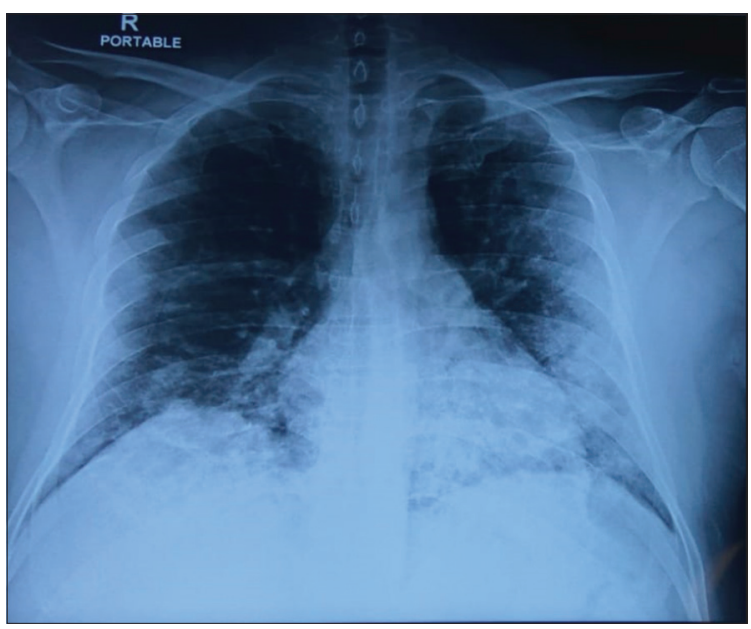

Figure 4: Predose chest X-ray image (on June 4, 2020)

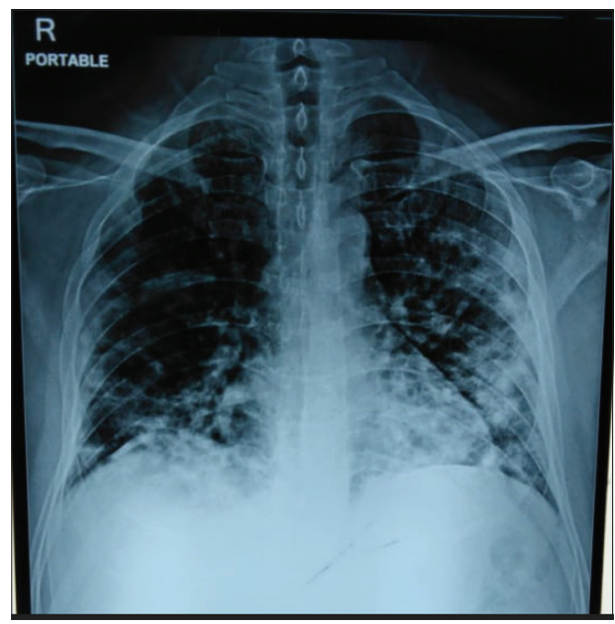

Figure 5: Postdose chest X-ray image (on June 9, 2020, 5-days postitolizumab infusion)

An ordinal scale for clinical improvement, published by the WHO, was used to score the patient status. ${ }^{[9]}$

Itolizumab has been approved and marketed in India for moderate-to-severe plaque psoriasis. It has been found to

\begin{tabular}{llc}
\hline $\begin{array}{l}\text { Table 1: World Health Organizations ordinal scale for } \\
\text { clinical improvement }\end{array}$ & Score \\
\hline $\begin{array}{l}\text { Patient } \\
\text { state }\end{array}$ & Descriptor & 0 \\
\hline Uninfected & No clinical or virological evidence of infection & 0 \\
Ambulatory & No limitation of activities & 1 \\
& Limitation of activities & 2 \\
Hospitalized & Hospitalized, no oxygen therapy & 3 \\
mild disease & Oxygen by mask or nasal prongs & 4 \\
Hospitalized & Noninvasive ventilation or high flow oxygen & 5 \\
severe & Intubation and mechanical ventilation & 6 \\
disease & Ventilation + additional organ & 7 \\
& support - pressors, RRT, ECMO & 8 \\
Dead & Death &
\end{tabular}

RRT: Renal replacement therapy, ECMO: Extracorporeal membrane oxygenation

reduce inflammation by blocking the CD6 receptor and thereby inhibiting various cytokines. ${ }^{[10]}$ Similar inflammatory responses have been reported in moderate-to-severe COVID-19 patients, leading to poor prognosis. ${ }^{[6]}$

Based on this, as this patient showed high levels of pro-inflammatory markers and deterioration in spite of the best supportive care, a decision was taken to administer itolizumab.

A single dose of itolizumab at $1.6 \mathrm{mg} / \mathrm{kg}$ led to a significant decrease in CRP and ferritin levels $(85.96 \%$ and $24.48 \%$, respectively) with clinical and radiological improvement. The patient's ordinal score also showed a decline over time. The oxygen requirements of this patient changed from $12-14 \mathrm{~L} / \mathrm{min}$ to 4-6 L/min on the $5^{\text {th }}$ day, and he was off oxygen on the $6^{\text {th }}$-day postinfusion of itolizumab.

In this case report, itolizumab is found to be not only effective in reducing inflammatory markers and the need for oxygen but also led to concomitant radiological improvement and recovery in this COVID-19 patient in a real-world setting. The use of itolizumab offers a potential treatment option by targeting CD6.

On July 10, 2020, itolizumab has been granted restricted emergency authorization in India for the treatment of cytokine release syndrome (CRS) in moderate-to-severe ARDS due to COVID-19 by the Drug Controller General of India.

\section{ConcLusion}

With itolizumab treatment, the patient showed a decline in CRP, ferritin, and oxygen requirement, along with radiological and clinical improvement. Itolizumab is found to be effective in reducing hyperinflammation, leading to a recovery in this COVID-19 patient with moderate-to-severe disease. While no approved or evidence-based treatment options are available, itolizumab promises potential in the treatment of CRS in moderate-to-severe ARDS due to COVID-19. Larger studies can further validate these findings. 


\section{Declaration of patient consent}

The authors certify that they have obtained all appropriate patient consent forms. In the form, the patient has given his consent for his images and other clinical information to be reported in the journal. The patient understands that his name and initials will not be published, and due efforts will be made to conceal identity, but anonymity cannot be guaranteed.

\section{Financial support and sponsorship}

Nil.

\section{Conflicts of interest}

There are no conflicts of interest.

\section{RefEREnCES}

1. Tay MZ, Poh CM, Rénia L, MacAry PA, Ng LF. The trinity of COVID-19: Immunity, inflammation and intervention. Nat Rev Immunol 2020;20:363-74.

2. Rodriguez PC, Torres-Moya R, Reyes G, Molinero C, Prada D, Lopez AM, et al. A clinical exploratory study with itolizumab, an anti-CD6 monoclonal antibody, in patients with rheumatoid arthritis. Results Immunol 2012;2:204-11.
3. Menon R, David BG. Itolizumab-A humanized anti-CD6 monoclonal antibody with a better side effects profile for the treatment of psoriasis. Clin Cosmet Investig Dermatol 2015;8:215-22.

4. Jayaraman K. Biocon's first-in-class anti-CD6 mAb reaches the market. Nat Biotechnol 2013;31:1062-3

5. Verity R, Okell LC, Dorigatti I, Winskill P, Whittaker C, Imai N, et al. Estimates of the severity of coronavirus disease 2019: A model-based analysis. Lancet Infect Dis 2020;20:669-77.

6. Mehta P, McAuley DF, Brown M, Sanchez E, Tattersall RS, Manson JJ, et al. COVID-19: Consider cytokine storm syndromes and immunosuppression. Lancet 2020;395:1033-4.

7. Zeng F, Huang Y, Guo Y, Yin M, Chen X, Xiao L, et al. Association of inflammatory markers with the severity of COVID-19: A meta-analysis. Int J Infect Dis 2020;96:467-74.

8. Facciorusso A, del Prete V, Antonino M, Neve V, Crucinio N, di Leo A, et al. Serum ferritin as a new prognostic factor in hepatocellular carcinoma patients treated with radiofrequency ablation. J Gastroenterol Hepatol 2014;29:1905-10.

9. WHO R\&D Blueprint: Novel Coronavirus. COVID-19 Therapeutic Trial Synopsis. Available from: https:/www.who.int/publications/i/item/ covid-19-therapeutic-trial-synopsis. [Last accessed on 2020 Jun 23].

10. Krupashankar DS, Dogra S, Kura M, Saraswat A, Budamakuntla L, Sumathy TK, et al. Efficacy and safety of itolizumab, a novel anti-CD6 monoclonal antibody, in patients with moderate to severe chronic plaque psoriasis: Results of a double-blind, randomized, placebo-controlled, phase-III study. J Am Acad Dermatol 2014;71:484-92. 